\title{
1 High-resolution in situ measurement of nitrate in runoff from the 2 Greenland Ice Sheet
}

3 Authors: Alexander D. Beaton ${ }^{1}$, Jemma L. Wadham ${ }^{2}$, Jon Hawkings ${ }^{2}$, Elizabeth A. Bagshaw ${ }^{3}$, Guillaume

4 Lamarche-Gagnon ${ }^{2}$, Matthew C. Mowlem ${ }^{1,}$ Martyn Tranter ${ }^{2}$

$5 \quad$ 1. National Oceanography Centre, European Way, Southampton, SO14 3ZH

$6 \quad$ 2. Bristol Glaciology Centre, University of Bristol, University Road, Bristol, BS8 1SS

7 3. School of Ocean and Earth Sciences, Cardiff University, Cardiff, CF10 3AT

8 *Corresponding author: a.beaton@noc.ac.uk, Tel: +442380596268

\section{Abstract}

10 We report the first in situ high-resolution nitrate time series from two proglacial meltwater rivers draining

11 the Greenland Ice Sheet, using a recently developed submersible analyser based on lab-on-chip (LOC)

12 technology. The low sample volume (320 $\mu \mathrm{L})$ required by the LOC analyser meant that low concentration

13 (few to sub $\mu \mathrm{M}$ ), highly turbid subglacial meltwater could be filtered and colourimetrically analysed in

14 situ. Nitrate concentrations in rivers draining Leverett Glacier in South-West Greenland and Kiattuut

15 Sermiat in Southern Greenland exhibited a clear diurnal signal and a gradual decline at the

16 commencement of the melt season, displaying trends that would not be discernible using traditional daily

17 manual sampling. Nitrate concentrations varied by $4.4 \mu \mathrm{M}(+/-0.2 \mu \mathrm{M})$ over a 10-day period at Kiattuut

18 Sermiat and $3.0 \mu \mathrm{M}(+/-0.2 \mu \mathrm{M})$ over a 14 day period at Leverett Glacier. Marked changes in nitrate

19 concentrations were observed when discharge began to increase. High resolution in situ measurements

20 such as these have the potential to significantly advance the understanding of nutrient cycling in remote

21 systems, where the dynamics of nutrient release are complex but are important for downstream

22 biogeochemical cycles. 


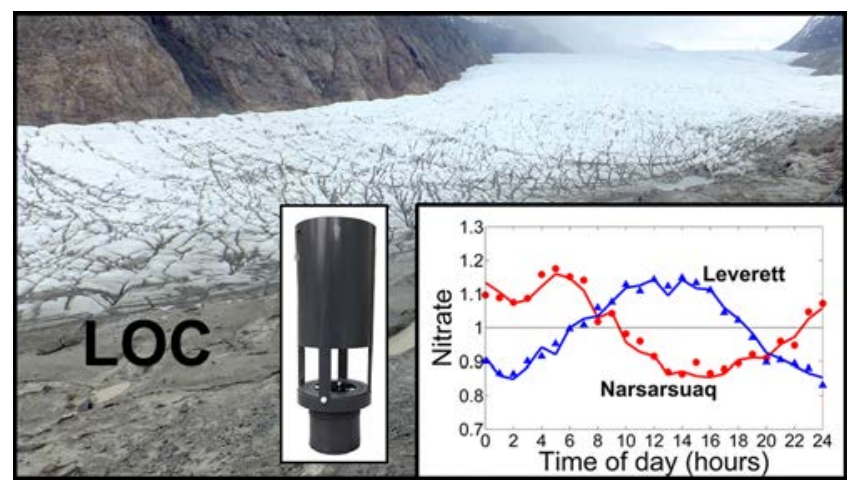

\section{Introduction}

27 There is now a growing body of evidence to suggest that glacial environments are active and significant components of the global nitrogen cycle. Evidence exists for nitrification and nitrogen fixation on glacier surfaces ${ }^{1,2}$, while both nitrification and nitrate reduction ${ }^{3,4}$ have been shown to occur in subglacial sediments. Export of nitrogen from ice sheets through glacial meltwater may fertilise downstream marine ecosystems ${ }^{5}$, potentially helping to support the presence of near-ice blooms ${ }^{6}$ and high rates of primary production ${ }^{7}$ around the Greenland Ice Sheet. Annual dissolved inorganic nitrogen flux from the

33 Greenland Ice Sheet has been estimated at $30-40 \mathrm{Gg}^{5}$, which is comparable to large Arctic rivers yet 34 supplies different ocean basins.

To date, the measurement of nutrients in glacial meltwater has taken place exclusively through the manual

37 collection of discrete samples and subsequent laboratory-based analysis (typically through automated 38 colourimetric methods (e.g. ${ }^{1}$ ) or ion chromatography (e.g. ${ }^{3,5,8}$ ). This approach is expensive and time39 consuming, and results in sporadic and/or low temporal-resolution datasets. Hence, the chemistry of 40 glacial meltwater, including that reaching the polar oceans, is chronically under-sampled, and information 41 on processes involved in nutrient cycling is lacking. This is likely to have important consequences for the 42 accuracy of estimated nutrient fluxes from ice sheets and glaciers into the fjords and polar oceans ${ }^{9}$, and 43 also on predictions about how climate-driven changes in ice-sheet run-off might influence downstream 44 primary production ${ }^{8}$. 
High-resolution, quasi-continuous in situ measurements enable better understanding of nutrient fluxes and temporal dynamics in glacial systems. In situ sensors and analysers can be deployed in remote and

47 inaccessible locations where traditional manual sampling techniques would be logistically difficult and

48 potentially dangerous. There have so far been few applications (e.g. ${ }^{10}$ ) of in situ chemical sensors to the 49 measurement of glacial meltwater, and none for the measurement of nitrate and other nutrients. The harsh

50 ambient environmental conditions, high sediment loads and low concentrations found in glacial

51 environments are a challenge for conventional sensor technologies ${ }^{11}$.

52 Several studies to date (e.g. ${ }^{12-14}$ ) have used UV absorbance nitrate sensors to conduct high temporal 53 resolution in situ measurements in freshwater streams and rivers. UV absorbance sensors require no 54 reagents, and have been deployed for extended periods (several months). Nitrate concentrations are 55 typically sub- to low $\mu \mathrm{M}$ in glacial meltwaters ${ }^{3,5,15}$, hence the relatively poor limit of detection (LOD) 56 e.g. $0.5 \mu \mathrm{M}$ for SUNA V2 - and accuracy (e.g. +/- $2 \mu \mathrm{M}$ for SUNA V2) make UV absorbance systems

57 largely unsuitable. Likewise, ion selective electrodes have been used in rivers to measure nitrite and 58 nitrate ${ }^{16,17}$, but poor LOD (e.g. $0.5 \mu \mathrm{M}$ ) and drift make them unsuitable for pristine glacial environments. Reagent based colourimetric analysers offer an alternative technology for in situ measurement of nitrate,

61 and several other parameters (e.g. ${ }^{18-21}$ ). These systems miniaturise standard laboratory-based analysis 62 techniques, and have been deployed in rivers, estuaries ${ }^{22}$, marine environments ${ }^{23}$, and more recently in 63 an oligotrophic arctic stream ${ }^{24}$. The creation of an absorbing dye, with highly specific reagents, produces 64 a robust and sensitive measurement technique, resulting in high precision and lower LODs. Furthermore, 65 the ability to carry and analyse on-board standards leads to high-accuracy measurements and drift 66 correction. Standard wet chemical (reagent) assays have been adapted to in situ use for a number of 67 biogeochemical parameters, such as nitrate, nitrite, ammonia, phosphate and dissolved iron. Despite these 68 advantages, reagent based sensors are typically large and bulky, and consume large amounts of power and 69 reagents, making them unsuitable for remote long-term operation, especially in remote environments. 
Recent work has shown that in situ reagent-based colourimetric sensors can be enhanced using

71 microfluidics ${ }^{25,26}$. Implemented through lab-on-a-chip (LOC) technology, microfluidics (the

72 manipulation of small volumes of fluids through microchannels, typically tens to hundreds of $\mu$ m wide)

73 allows reduced reagent consumption, lower power consumption and a decrease in the physical size and

74 weight of chemical analysis systems. This development has the potential to expand the applicability of in

75 situ colourimetric analysers to a wide variety of deployment scenarios that were unsuitable for the

76 previous generation of systems. The measurement of glacial meltwater is a prime example.

77 Glacial environments present a unique set of challenges for the application of in situ chemical analysis

78 systems, including high suspended sediment loads, low analyte concentrations, low ambient temperatures,

79 remote deployment locations and the necessity for stand-alone low-power operation. Glacier runoff is

80 highly turbid (e.g. up to $13.1 \mathrm{~g} / \mathrm{l}^{27}$ ), presenting problems for optical measurement systems and filters.

81 However, microfluidic systems use low sample volumes (in this case $\sim 320 \mu \mathrm{L}$ ), allowing proglacial

82 meltwater to be filtered to the point that it is optically clear and free of particles $(>0.45 \mu \mathrm{m})$ without

83 requiring excessive filter changes. Low fluid volumes mean that less energy is spent on pumping,

84 typically the main power-draw in fluidic analysers ${ }^{26}$, resulting in low power consumption, which is

85 essential for remote deployment. Remote locations also mean that sensors may need to be carried on foot

86 to deployment sites, making lightweight, portable devices (such as microfluidic sensors) essential.

87 Here, we report the first applications of a microfluidic LOC colourimetric sensor for the in situ

88 measurement of nitrate in meltwater rivers draining the Greenland Ice Sheet. This work represents the

89 first measurement of nitrate in situ and at high temporal resolution in glacial runoff. The limit of detection

$90(0.025 \mu \mathrm{M})$ and range $(0.025$ to $350 \mu \mathrm{M})$ of the system are adequate and suitable for the nitrate

91 concentrations measured in the glacial runoff, and the power consumption (1.8 W) is low enough that the

92 analyser can be deployed in remote locations with power provided by a solar-charged battery.

\section{$93 \quad$ Materials and Methods}


LOC analysers were deployed to measure runoff emerging from two contrasting outlet glaciers of the Greenland Ice Sheet.

97 The first deployment was from $26^{\text {th }}$ May to $6^{\text {th }}$ June, 2013, in runoff emerging from Kiattuut Sermiat (KS, $9861.2 \mathrm{~N}, 45.3 \mathrm{~W}$, Figure 1A), a land terminating outlet glacier of the Greenland Ice Sheet located $\sim 8 \mathrm{~km}$ 99 from Narsarsuaq in southern Greenland (Figure 1A), estimated to cover an area of $36 \mathrm{~km}^{2}{ }^{28}$. Subglacially derived meltwater emerging from the glacier discharges into a proglacial lake, $\sim 0.5 \mathrm{~km}^{2}$ and $12 \mathrm{~m}$ deep at 101 its centre ${ }^{29}$, which in turn flows into a proglacial river (the Kuusuaq river) leading into the fjord. The 102 LOC analyser was deployed at a site approximately $1 \mathrm{~km}$ downstream of the lake, and was programmed to take a measurement of nitrate plus nitrite (referred to here as $\Sigma \mathrm{NO}_{\mathrm{x}}$ ) approximately every 20 minutes.

104 The second deployment was from $26^{\text {th }}$ May to $9^{\text {th }}$ June, 2015, in runoff emerging from Leverett Glacier 105 (LG, 67.06N, 50.17W, Figure 2B). LG is a large polythermal-type land terminating outlet glacier in west 106 Greenland draining a catchment area $\sim 600 \mathrm{~km}^{230}$. Meltwaters emerge from a well-defined portal located 107 on the northern side of the glacier terminus. The resultant proglacial river flows downstream into the 108 Watson River, which eventually enters Sondre Stromfjord. The large catchment is hydrologically and geologically ${ }^{28}$ representative of a large area of the Greenland Ice Sheet, which, combined with the single well defined meltwater river, makes LG a more suitable site for studying nutrient export dynamics. The

111 analyser at LG was programmed to perform a $\Sigma \mathrm{NO}_{\mathrm{x}}$ measurement every 1 hour.

\section{LOC analyser}

113 The LOC system performs automated colourimetric $\Sigma \mathrm{NO}_{\mathrm{x}}$ analysis on a polymer microfluidic chip using 114 the Griess assay and cadmium reduction ${ }^{25}$. The chip contains a network of microchannels (dimensions $115150 \mu \mathrm{m} \times 300 \mu \mathrm{m}$ ) and two sequential on-chip optical absorption cells (2.5 mm and $25 \mathrm{~mm}$ in length). 116 The analyser has a limit-of-detection of $0.025 \mu \mathrm{M}$ and a linear dynamic range up to $350 \mu \mathrm{M}$. Fluid 
117 handling is performed by a custom-built three-channel syringe pump and fourteen solenoid valves 118 attached directly to the chip, and the system is controlled using a custom microcontroller-based 119 electronics package. The development and first deployments of the LOC analyser have been described 120 previously ${ }^{25,31}$.Two different deployment and filtering set-ups were used in this experiment. At KS, the 121 LOC sensor was housed in a water-tight Perspex tube mounted in a plastic box on the bank beside the 122 proglacial river. The shallow depth of the water meant that the sensor was kept on the riverbank, and 123 water was delivered to it using a lift pump and dual filtering system. At LG, where the channel was 124 deeper, the sensor was housed in a PVC tube, and submerged so that the filter inlet was below the 125 waterline. A single $0.45 \mu \mathrm{m}$ inline syringe filter with prefilter (Millex-HPF PTFE, Merck Millipore) was used at the inlet to the sensor. The sensor housings were placed in perforated plastic boxes which were 127 weighed down with rocks collected from the shoreline.

128 Reagents, calibration standards and collected waste were stored in $500 \mathrm{ml}$ Flexboy bags (Sartorius129 Stedim). All liquid that passed through the system was collected as waste, ensuring that no chemical 130 waste from the analyser (including that which passed through the cadmium reduction tube) entered the 131 environment. The system operated at a flow rate of $165 \mu \mathrm{L} / \mathrm{min}$ (per syringe). Each measurement was 132 accompanied by a blank measurement (MilliQ water) and the measurement of a $3 \mu \mathrm{M}$ nitrate standard, 133 allowing continuous calibration throughout the deployment, thus compensating for changes in ambient 134 temperature. Reagents and standards were prepared as described previously ${ }^{25}$. Blank and standard 135 solutions were fixed using $0.01 \%$ chloroform. Analytical uncertainties in the measurements performed by 136 the LOC analyser were estimated by calculating twice the running standard deviation $(n=5)$ of the 137 measurements of the $3 \mu \mathrm{M}$ standard ${ }^{32}$ and averaging for the deployment period.

\section{Lift pump}

139 At KS, a miniature peristaltic pump (100 series, Williamson Manufacturing Company Limited), mounted in a water-tight box next to the sensor, was used to lift proglacial meltwater from the stream up to a t-

141 piece mounted at the input via a $4.3 \mathrm{~m}$ long R-3603 Tygon tube (1.6 mm internal diameter). The pump 
operated at a flow rate of $1.4 \mathrm{~mL} / \mathrm{min}$, resulting in an 8 minute delay between water leaving the proglacial stream and reaching the t-piece. The flow rate was chosen as a compromise between minimising both the amount of high-turbidity water passing through the cross-flow pre-filter in the river (see below), and the 145 delay between water leaving the proglacial river and reaching the analyser. A cross-flow pre-filter was 146 placed in the river at the entrance to the Tygon tubing. The pre-filter was created by slicing open a $50 \mathrm{~mm}$ 147 diameter MILLEX-GP (Merck Millipore) filter unit, removing the $0.22 \mu \mathrm{m}$ pore-size filter membrane and 148 replacing it with a $1 \mu \mathrm{m}$ pore size filter membrane. The outside edge of the filter membrane was secured 149 to the inside of one half of the filter unit using Araldite epoxy, and the remaining half of the filter unit was 150 discarded. This created an open-faced cross-flow filter (Figure 2B) which was placed into the proglacial 151 stream, where the flow of water helped clean the exposed face of filter. Pre-filtered meltwater 152 subsequently passed through an inline $0.45 \mu \mathrm{m}$ Millex-HP (PES membrane, Merck Millipore) filter on 153 entrance to the LOC analyser.

\section{Manually collected samples}

155 At KS, two independent sets of manually collected proglacial stream nutrient samples were taken during 156 the sensor deployment period. These were filtered through $0.45 \mu \mathrm{m}$ syringe filters and frozen for later 157 analysis ${ }^{5}$. One set was analysed using a QuAAtro segmented flow analyser, and the other was analysed using a Thermo Scientific Dionex Ion Chromatograph ICS5000+ Capillary system with IonPac AS-11 HC anion-exchange column. In addition, six supraglacial stream samples were taken from meltwater entering moulins close to the ice margin (analysed using ion chromatography as above). At LG, one set of 161 samples was filtered $(0.45 \mu \mathrm{m})$, frozen, and analysed colourimetrically using a Thermo Gallery and the 162 hydrazine reduction method (precision based on five replicates of a $1.42 \mu \mathrm{M}$ standard was $+/-1.1 \%$, 163 accuracy was $+4.2 \%)$. A second set of samples was filtered $(0.45 \mu \mathrm{m})$, stored chilled, and analysed using 164 ion chromatography (as above). 
167 (EC) (Campbell 247) and pH (Honeywell Durafet, temperature compensated) were deployed alongside 168 the LOC sensor and linked to Campbell CR1000 loggers located in plastic housings on the riverbanks. An 169 additional station (approximately 150 m downstream) recorded air temperature (Campbell 107), water 170 stage (Druck pressure transducer) and photosynthetically active radiation (PAR) at KS. For part of this 171 deployment, an oxygen optode (Aanderaa 3830) was deployed approximately $200 \mathrm{~m}$ upstream from the 172 LOC analyser. Sensors for PAR and dissolved oxygen (Aanderaa 3830) were co-located with the LOC 173 analyser and operated for the duration of the deployment at LG. Fluorometric dye (Rhodamine-WT)

174 traces conducted at a wide variety of water levels were used to convert water stage measurements into 175 meltwater discharge values at both sites ${ }^{33,34}$ using previously published methods ${ }^{30}$ (see Supporting 176 Information for additional details on discharge measurements).

177 The LOC analyser, lift pump and additional sensors and loggers were all powered by a 20 Ah solar178 charged absorbent glass mat (AGM) lead acid battery mounted in a waterproof box beside the river.

\section{Results}

\section{Kiattuut Sermiat (KS)}

181 The LOC analyser recorded $\Sigma \mathrm{NO}_{\mathrm{x}}$ concentrations in the proglacial stream over a 10-day period (Figure $1823 \mathrm{~A}) . \Sigma \mathrm{NO}_{\mathrm{x}}$ averaged $3.64 \mu \mathrm{M}+/-0.2 \mu \mathrm{M}$, and varied between 1.39 and $5.79 \mu \mathrm{M}(+/-0.2 \mu \mathrm{M})$. During 183 this period, water temperature (Figure 3B) varied between 1.16 and $3.15^{\circ} \mathrm{C}\left(+/-0.4^{\circ} \mathrm{C}\right)$ and air 184 temperature (Figure 3B) between 1.5 and $15.2^{\circ} \mathrm{C}\left(+/-0.4^{\circ} \mathrm{C}\right)$. Electrical conductivity (Figure 3C) varied 185 between 46.2 and $50.6 \mu \mathrm{Scm}^{-1}(+/-10 \%)$ and $\mathrm{pH}$ (Figure 3D) between 7.77 and $8.26(+/-0.1)$. An 186 equipment failure meant that dissolved oxygen data (Figure 3C) is only available from the first three days 187 of deployment, but this showed variations between 102.7 and $114.2 \%$ (+/- $2.5 \%$ ) of air saturation. 
188 Clear diurnal cycles in $\Sigma \mathrm{NO}_{\mathrm{x}}$ concentration were observed. Days 1 to 4 show a slight downward trend

189 (average decrease of $0.31 \mu \mathrm{M}$ per day), with a mean value of $3.73 \mu \mathrm{M}$ and diurnal variations with a mean

190 amplitude of $1.27 \mu \mathrm{M}$. Hydrological conditions were relatively stable during this period, with discharge

191 averaging $7.33 \mathrm{~m}^{3} \mathrm{~s}^{-1}(+/-12 \%)$ and increasing slowly (by $0.27 \mathrm{~m}^{3} \mathrm{~s}^{-1}$ per day) while exhibiting average

192 daily cycles of $1.16 \mathrm{~m}^{3} \mathrm{~s}^{-1}$ in amplitude. $\mathrm{pH}$ showed diurnal variations (amplitude of $\mathrm{pH} 0.24$ ), as did

193 water temperature $\left(1.4^{\circ} \mathrm{C}\right)$ and EC $\left(0.74 \mu \mathrm{Scm}^{-1}\right)$. Elevated night-time temperatures on Day 153 marked

194 the beginning of a large increase in discharge, which was associated with a drop in conductivity and

195 dampening of diurnal $\mathrm{pH}$ cycles. This coincided with an increase in the amplitude of daily $\Sigma \mathrm{NO}_{\mathrm{x}}$

196 concentrations, which on the final two days peaked at $5.79 \mu \mathrm{M}$ and dropped to $1.39 \mu \mathrm{M}$. Discharge

197 reached $31.4 \mathrm{~m}^{3} \mathrm{~s}^{-1}$ by the end of the deployment period and was continuing to rise. Nitrite $\left(\mathrm{NO}_{2}^{-}\right)$made

198 up no more than $1.8 \%$ of the $\Sigma \mathrm{NO}_{\mathrm{x}}$ signal in collected water samples (mean=1.14\%, $\mathrm{n}=14$ ), showing that

199 the $\Sigma \mathrm{NO}_{\mathrm{x}}$ signal was dominated by nitrate $\left(\mathrm{NO}_{3}{ }^{-}\right)$. There was a visible build-up of sediment on the face of

200 the cross-flow filter, yet the pre-filtering system was able to continuously deliver a $1 \mu \mathrm{m}$ pre-filtered

201 sample stream to the analyser for the duration of the deployment. However, sediment build-up on the

202 surface of the pre-filter caused gas bubbles to appear in the sample stream because of sample outgassing

203 at the reduced pressure between the filter and the pump. Occasionally, a bubble would be drawn into

204 analyser, resulting in an anomalous reading. Out of the $386 \Sigma \mathrm{NO}_{\mathrm{x}}$ measurements conducted by the

205 analyser at KS, 31 (<10 \%) were excluded due to the presence of bubbles drawn in through the sample

206 inlet. Gaps in the dataset from KS were caused by a fault with the sensor pump, which was subsequently

207 identified and fixed, preventing reoccurrence on subsequent deployments.

208 Leverett Glacier (LG)

209 The LOC analyser operated continuously over a 14 day period, recording $\Sigma \mathrm{NO}_{\mathrm{x}}$ concentrations between

2100.96 and $3.98 \mu \mathrm{M}(+/-0.2 \mu \mathrm{M})$ (Figure 4A) and yielding a much more complete dataset that that achieved

211 at KS. Conductivity ranged from 5.45 to $44.55 \mu \mathrm{S} \mathrm{cm}^{-1}$ (+/- 10\%) (Figure 4B), pH from 6.45 to 7.31 (+/- 

temperature dropped to as low as $-3.22{ }^{\circ} \mathrm{C}$ and reached a maximum of $12.0^{\circ} \mathrm{C}$, while water temperature ranged from 0.02 to $4.41^{\circ} \mathrm{C}$ (Figure 4C). $\Sigma \mathrm{NO}_{\mathrm{x}}$ concentrations showed a gradual downward decline over 215 the first six days $(0.31 \mu \mathrm{M}$ per day). High air temperatures on Day 151 prompted a sharp increase in 216 discharge, which was followed by a gradual increase in $\Sigma \mathrm{NO}_{\mathrm{x}}$ concentration for the remaining eight days. 217 A clear diurnal signal in $\Sigma \mathrm{NO}_{\mathrm{x}}$ concentrations was recorded again (mean amplitude $0.75 \mu \mathrm{M}$ ), peaking at 14:00 and reaching a trough at 02:00. Manual samples were collected at higher temporal resolution than 219 at KS (up to 3 times per day), and show good agreement with the LOC sensor, allowing us to validate the 220 short-term variations measured by the sensor (Figure 4A). LG exhibited strong diurnal cycles in 221 conductivity (average amplitude of $13.30 \mu \mathrm{S} \mathrm{cm}^{-1}$ ) compared to KS, where the diurnal conductivity cycles 222 were less pronounced (average amplitude $<1 \mu \mathrm{S} \mathrm{cm}^{-1}$ ). Water temperature exhibited a sharp increase (of 223 up to $4^{\circ} \mathrm{C}$ ) during the day and returned to a background level of $\sim 0.1^{\circ} \mathrm{C}$ during the night. Diurnal cycles 224 of both water temperature and oxygen saturation were dampened as discharge increased toward the end of 225 the deployment period. We found that it was not necessary to change the filter for the duration of the 226 deployment at LG, despite not using the lift-pump and cross-flow filter setup. Out of 321 measurements 227 conducted by the LOC sensor during the 14 day period, 10 were removed as outliers. Linear regression analysis shows strong correlation between the frozen samples that were analysed 229 colourimetrically and the measurements performed by the LOC sensor ( $\mathrm{LOC}=(0.95+/-0.17) *$ sample + $2300.04+/-0.4, p<0.05, R^{2}=0.82, n=33$; Supporting Information Figure S1). There is no systematic offset, 231 and the linear regression fit between the LOC sensor and samples is not statistically different to a 1:1 line. 232 Despite demonstrating similar trends, the non-frozen samples (analysed using ion chromatography) show 233 a less convincing statistical agreement with the LOC sensor $($ LOC $=(0.65+/-0.22) *$ sample $+0.9+/-0.5$, $234 \mathrm{p}<0.05, \mathrm{R}^{2}=0.57, \mathrm{n}=29$; Supporting Information Figures S1 and S2), which could potentially be due to 235 sample degradation during storage. 
The daily cycle for each of the measured parameters during both deployments is compared in Figure 5. over a single 24 hour period. Data shown is for the full deployment period at LG and for the

241 hydrologically stable period before Day 153 (where there are fewer gaps in the data) at KS.

242 Diurnal cycles for the measured physical parameters (air temperature, water temperature and PAR)

243 display similar properties at KS and LG, although at LG water temperature has no defined trough and 244 stays low (close to zero - Figure 4C) between 0:00 and 06:00. However, there are marked differences 245 between KS and LG for several of the other measured chemical parameters, including $\Sigma \mathrm{NO}_{\mathrm{x}} . \Sigma \mathrm{NO}_{\mathrm{x}}$ 246 concentrations peaked at 05:00 and reach a minimum at 15:30 at KS, while they peaked at 14:00 and 247 reached its minimum at 02:00 at LG. At KS, conductivity reached its peak at 07:00 and its trough at 248 17:00, while at LG conductivity peaked at 12:00 at reached its minimum at 21:00. The peak in water 249 level/discharge occurs slightly earlier at LG (20:00) compared to KS (23:00). At LG, pH followed a 250 similar trend to conductivity, peaking at 11:00 and reaching its minimum at 21:00, while at KS pH peaked 251 at 12:00 and reached its minimum at 0:00. At KS, DO saturation shows approximately the opposite trend 252 to $\Sigma \mathrm{NO}_{\mathrm{x}}$, peaking at around 15:00 and reaching a minimum at 5:00, while at LG DO saturation peaked at $253 \quad 13: 00$ and reached its lowest at midnight.

\section{Discussion}

255 The datasets described here represent the first high-resolution measurements of nitrate in melt waters

256 draining the Greenland Ice Sheet, and are also the first high-resolution nutrient data for glacial systems.

257 The LOC analysers resolved temporal dynamics of nitrate concentrations in proglacial rivers, revealing

258 the presence of diurnal cycles and short term trends, which were verified using sub-daily manual 259 sampling. The LOC analyser is a viable monitoring tool in this highly challenging environment. 
Nitrate concentrations in glacial runoff varied by up to $4.4 \mu \mathrm{M}$ over a 10-day period at KS and $3.0 \mu \mathrm{M}$ over a 14 day period at LG. This variability has not been captured by manual sampling to date, which enables more accurate estimation of nutrient export from glaciated areas due to the removal of potential bias when single, daily samples are collected at approximately the same time.

There are multiple factors that influence the nitrate concentrations in proglacial rivers draining the Greenland Ice Sheet, including the source of water (primarily snowmelt and ice melt), water flow paths (e.g. via subglacial and groundwater environments), the leaching of potential N-reservoirs (e.g. leaching of snowpack, soils and subglacial debris), and microbial processes along and within the flow paths, which may act as sinks or sources of nitrate ${ }^{5}$.

\section{High resolution chemical trends at Kiattuut Sermiat}

Clear diurnal cycles in the nitrate concentrations at KS are superimposed on a trend of slightly declining concentration over the first four days (Figure 3a). EC values $(\sim 50 \mu \mathrm{S} / \mathrm{cm})$ vary inversely with diurnal discharge (Figures 5e and g), although the diurnal variation is much less pronounced than at LG ( $<1 \mu \mathrm{S}$ $\mathrm{cm}^{-1}$ compared to $>10 \mu \mathrm{Sm}^{-1}$ ). This suggests minimal influence of daily meltwater inputs on diurnal variability in the stream, possibly due to a dampening effect by the proglacial lake. At this early stage in the melt season an efficient channelised subglacial drainage system had not yet developed ${ }^{33}$, and the lake was likely being fed by a combination of local snowmelt, supraglacial runoff, and small subglacial inputs from distributed drainage pathways. Biogeochemical processes in the proglacial lake were likely able to influence control over nutrient concentrations in the runoff.

Dissolved oxygen in the river was continually above $100 \%$ air saturation (Figure 3C) and fluctuated strongly on a daily basis, indicating an additional oxygen source within the proglacial stream or lake. Algal growth was observed in the stream and lake (visible on the sensor photographs in Figure 2B). Minimum daily concentrations of nitrate coincided maximum readings for PAR, DO and pH (Figure 5 a, b, c and f), suggesting that photosynthesis in the surface lake waters had a first order control on diurnal 
variations in nitrate. Observations of highest nitrate concentrations in early morning and lowest nitrate concentrations in the late afternoon are consistent with several other studies that have attributed nitrate fluctuations in streams to autotrophic production ${ }^{12,35,36}$.

287 Assuming the daily cycle in nitrate (mean amplitude $1.27 \mu \mathrm{M}$ ) was entirely a result of autotrophic assimilation and using a stoichiometric C:N ratio of 6.6:1, the carbon uptake rate due to primary production is estimated to be $8.4 \mathrm{mmol} \mathrm{C} \mathrm{m}^{-3} \mathrm{~d}^{-1}\left(79.5 \mathrm{mg} \mathrm{C} \mathrm{m}^{-3} \mathrm{~d}^{-1}\right)$. This is similar to the assimilation rate estimated during a similar study in an oligotrophic Arctic steam (10.8 $\mathrm{mmol} \mathrm{C} \mathrm{m}^{-3} \mathrm{~d}^{-1} 24$, assuming a 12 hour photoperiod), and on the lower end of reported ranges for large rivers of the world (0 - $132 \mathrm{mmol} \mathrm{C}$

$292 \mathrm{~m}^{-3} \mathrm{~d}^{-1}$, reviewed by ${ }^{37}$ and converted to daily rates assuming a 12 hour photoperiod). Lack of light 293 penetration would impede primary production in highly turbid proglacial streams.

294 EC fell more rapidly when discharge increased after Day153, and while maximum daily nitrate 295 concentrations persisted at $5 \mu \mathrm{M}$, minimum daily concentrations decreased from $\sim 3 \mu \mathrm{M}$ to $1 \mu \mathrm{M}$.

296 Decreases in nitrate as discharge increased are likely either associated with dilution from the connection 297 of a low-nitrate water source (e.g. increased supraglacial icemelt or the draining of an ice-marginal lake), 298 or an increased nitrate sink (e.g. increased productivity) in the lake and river system. Supraglacial waters 299 were all highly depleted in nitrate (mean $=0.08 \mu \mathrm{M}, \mathrm{SD}=0.05 \mu \mathrm{M}, \mathrm{n}=6$, see Supporting Information 300 Table S1) compared to concentrations in the proglacial river, and would therefore have a diluting effect on proglacial stream nitrate concentrations.

\section{High resolution chemical trends at Leverett Glacier}

303 Clear diurnal cycles were also evident in the nitrate concentrations at LG (Figure 4a). These were 304 superimposed on a trend of slightly declining concentration over the first six days. A major difference 305 with KS is that maximum daily nitrate concentrations at LG coincided with maximum DO, PAR and $\mathrm{pH}$ 306 (Figure 5 a, b, c and e), strongly suggesting that photosynthesis was not a first order control on diurnal 307 variations in nitrate at LG. Here, where there is no proglacial lake and EC variations are much more 
pronounced, diurnal variations in nitrate are more likely a result of dilution by the daily meltwater inputs.

The daily peak in nitrate is coincident with the peak in conductivity, which occurs at low flow, whereas high flow is coincident with the troughs in $\mathrm{pH}$ and conductivity. Dilute low-pH water is an indicator of

311 fresh snowmelt (e.g. ${ }^{38,39}$ ). The inferred fresh snowmelt pulse appears to be depleted in nitrate, while the

312 peak in nitrate is associated with higher EC, more concentrated water. Bulk snowmelt concentrations have

313 been previously recorded in this area as $1.03+/-0.30 \mu \mathrm{M}^{2}$. Rather than coming from the fresh daily pulse

314 of snowmelt, the daily nitrate peaks likely reflect groundwater enriched in nitrate (e.g. through microbial

315 nitrification ${ }^{40-42}$ ), which is then diluted by the fresh daily pulse of snowmelt. A marked increase in

316 discharge occurred on Day 152 coincided with a switch from decreasing to increasing nitrate

317 concentrations, which may be the influence of early subglacial meltwater. The evolution of the subglacial

318 drainage system from an inefficient system draining mostly overwinter stored waters to a more efficient

319 system allowing surface melt to transit rapidly at the glacier bed was not observed until day 170 (see ${ }^{34}$ ).

320 Hence, any runoff derived from the subglacial drainage system during the monitoring period (prior to Day

321 170) is composed of long residence time distributed system waters that have likely been in storage at the 322 glacier bed over winter. Subglacial environments are viable habitats for microbial life ${ }^{43,44}$, and previous 323 studies have reported microbial-driven nitrate production ${ }^{3,4}$ through nitrification of surface derived 324 ammonium in subglacial environments (this would require some oxygen to be present in the subglacial 325 system, potentially supplied via basal melting). There is also a potential geological source of ammonium 326 through rock comminution (e.g. ${ }^{45-47}$ ) which could then undergo nitrification. These processes could 327 enrich early subglacially derived meltwater with nitrate (e.g. ${ }^{5}$ ), and potentially explain the rise in nitrate 328 levels as discharge increases after Day 152. More concentrated subglacial waters and groundwater 329 continued to be diluted by fresh snowmelt during the day, explaining the continued diurnal nitrate signal.

331 Diurnal nitrate signals measured with in situ sensors have been reported previously for snowmelt streams, 332 and these have been attributed to either autotrophic uptake ${ }^{14}$ or increased soil water inputs ${ }^{24}$. This paper 333 reports the use of a novel in situ instrument to produce the first high-resolution automated nutrient 
measurements in glacial meltwater streams, in association with high-resolution measurements of pH, DO, PAR, EC, discharge, air temperature and water temperature. This combination of high resolution measurements is unprecedented in the literature, and gives insight into the interplay between physical,

337 hydrological and biogeochemical processes that would be hard to gain from manual, spot measurements.

338 The development and validation of robust in situ geochemical monitoring tools for cryospheric sciences

339 could have a major impact on our understanding of these remote, yet highly sensitive, ecosystems. This

340 study describes two relatively short term deployments, and future work will look to establish miniaturised

341 chemical analysers as long term monitoring tools in a range of hard-to-access glacial environments.

342 Potentially revealing applications include supraglacial waters (streams and lakes on the surface of the ice

343 sheet), subglacial environments (e.g. boreholes and subglacial lakes) and deployments underneath sea-ice.

344 Robust monitoring platforms have already been developed for these highly inaccessible environments

345 (e.g. the Lake Ellsworth probe ${ }^{48}$ and Cryoegg ${ }^{29}$ ), and future work could see their integration with high

346 performance chemical analysers. In addition to the nitrate analyser discussed here, similar tools are under

347 development for other nutrients (phosphate ${ }^{49,50}$ and silicate), trace metals (e.g. dissolved iron) and

348 carbonate system parameters.

\section{Acknowledgements}

350 This research is part of the UK NERC funded project DELVE (NERC grant NE/I008845/1). We thank

351 Andrew Tedstone, Jon Telling, Ashley Dubnick, David Chandler, Jade Hatton, Marek Stibal, Tyler

352 Kohler, Jakub Žárský and all those who assisted with fieldwork at KS and LG. We also thank Chris

353 Cardwell, David Owsianka, Gregory Slavik and other members of the Ocean Technology and

354 Engineering Group (OTEG) at NOC.

\section{Supporting Information Available}


356 Supporting information contains data from analysis of supraglacial meltwater samples at KS, details on

357 discharge measurements at KS and LG, details on LOD and calibration of the LOC sensor, and plots of

358 the relationship between the LOC sensor measurements at Leverett glacier and the data from the analysis

359 of the manually collected samples

360 This information is available free of charge via the Internet at http://pubs.acs.org

361

\section{Figures}

363 Figure 1: Map of deployment sites, showing A) the locations of the nitrate sensor (red star), gauging

364 station (black triangle) and oxygen optode (black circle), in relation to Kiattuut Sermiat, Narsarsuaq and

365 the fjord, and B) the site of the LOC sensor (red star) and gauging station (black triangle) at Leverett

366 Glacier. 


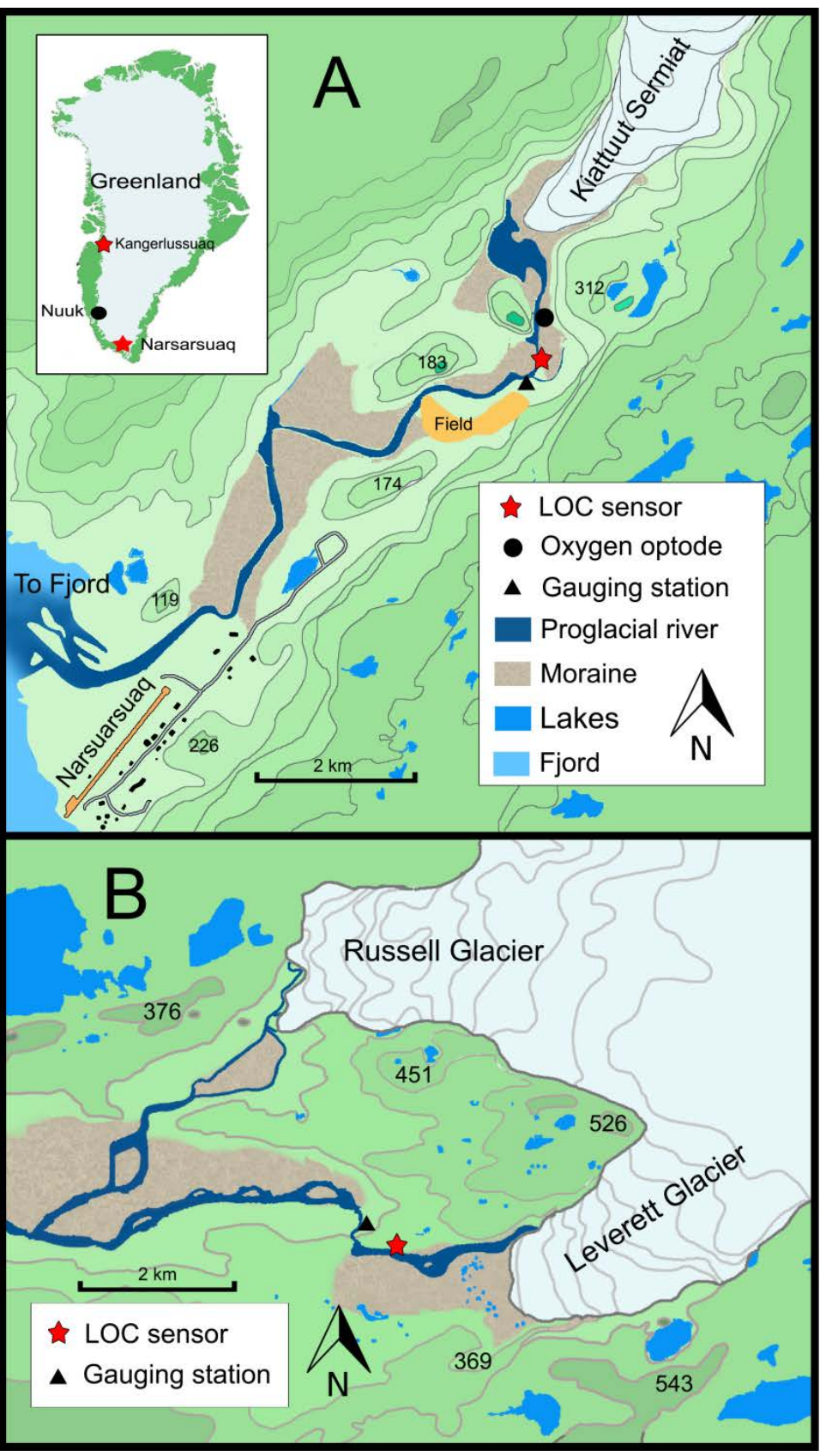

Figure 2: Photographs of the deployment sites showing: A) The proglacial stream at Kiattuut Sermiat with the glacier in the background (the LOC analyser was stationed close to the rocks in the foreground), B) The sensor head that was placed into the proglacial stream. The cross-flow filter inlet was connected

373 to Tygon tubing which led up to the lift pump and LOC analyser located on the riverbank. Also visible are the Honeywell Durafet pH probe and the Campbell Scientific conductivity/temperature probe. C) The

375 sensor deployment site at Leverett Glacier with the glacier in the background. D) The LOC sensor 


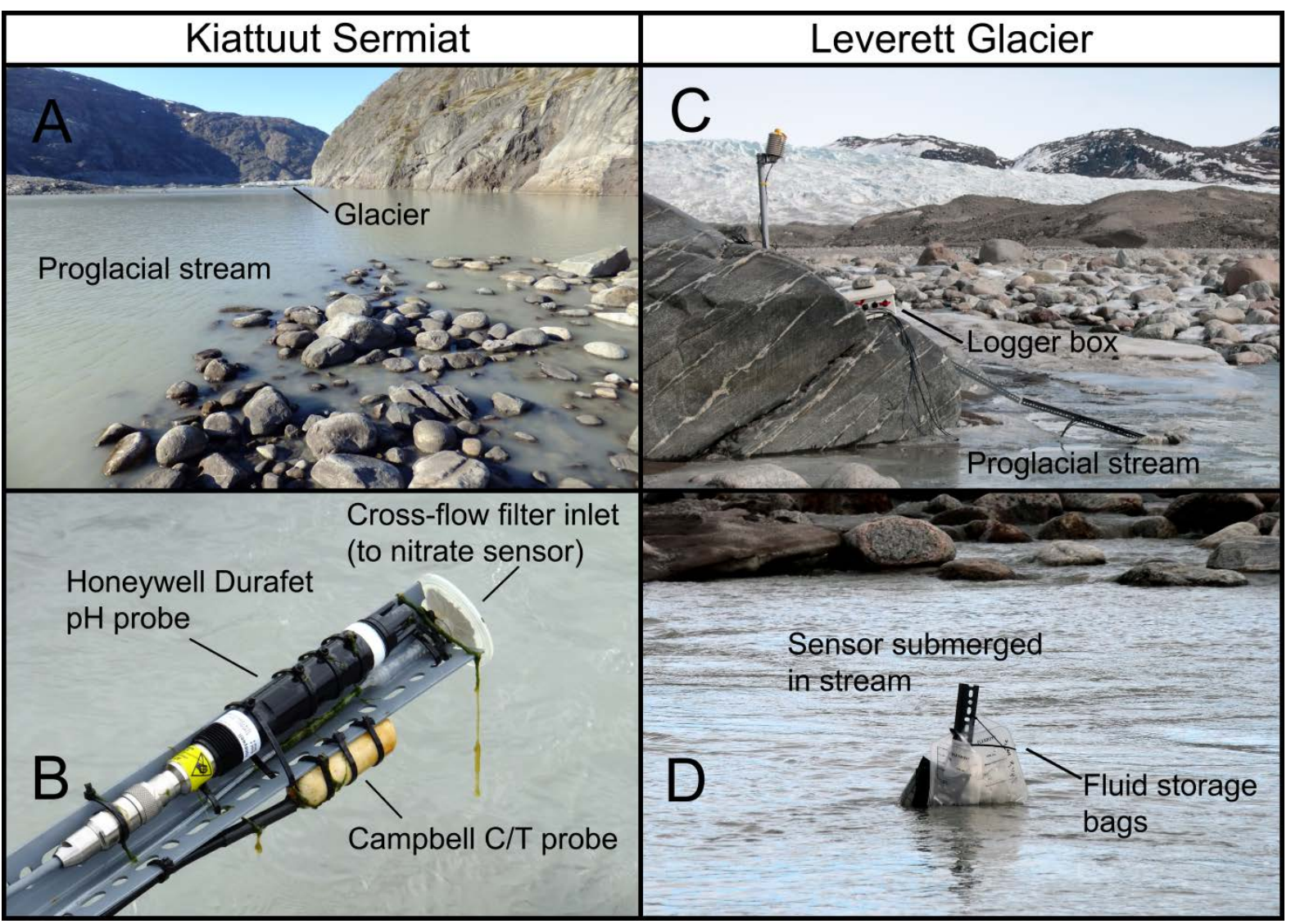

Figure 3: Time series data for all measured parameters at Kiattuut Sermiat glacier, Narsarsuaq, showing: 381 A) Nitrate plus nitrite data from the LOC analyser (blue circles) and manually collected samples analysed 382 using ion chromatography (green circles) and colorimetry (green triangles) as well as discharge (red line). 383 B) Water temperature (blue line) and air temperature (green line). C) Electrical conductivity (blue line) and dissolved oxygen saturation (green line). D) pH (blue line) and PAR (grey line). 

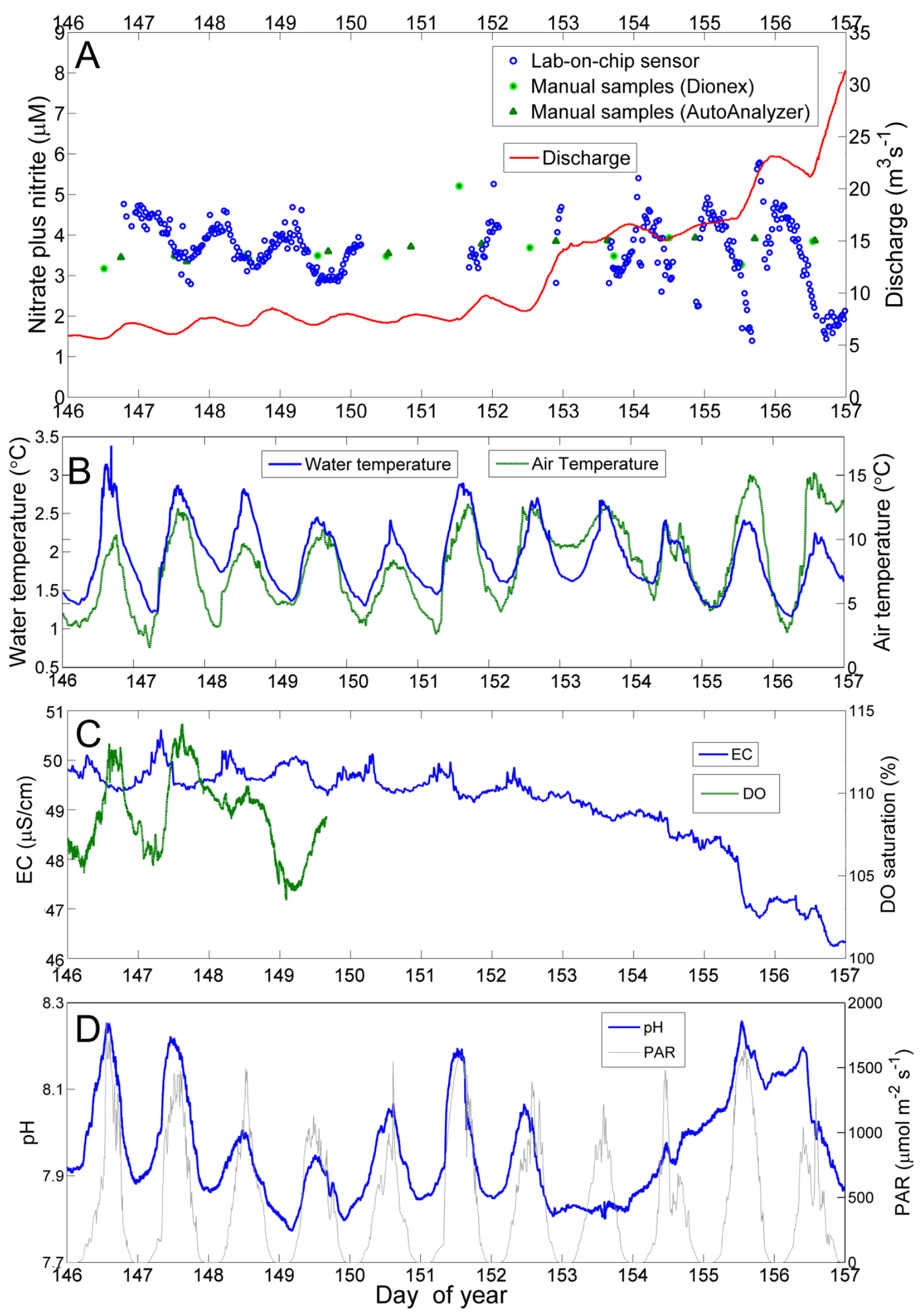
386 Figure 4: Time series data from the deployment of the LOC nitrate sensor at Leverett Glacier showing A)

387 Nitrate plus nitrite data from the LOC analyser (blue circles), manually collected samples that were frozen

388 and analysed colorimetrically (dark green circles) and discharge (red line). B) Water temperature (blue

389 line) and air temperature (green line). C) Electrical conductivity (blue line) and dissolved oxygen

390 saturation (green line). D: pH (blue line) and PAR (grey line). 

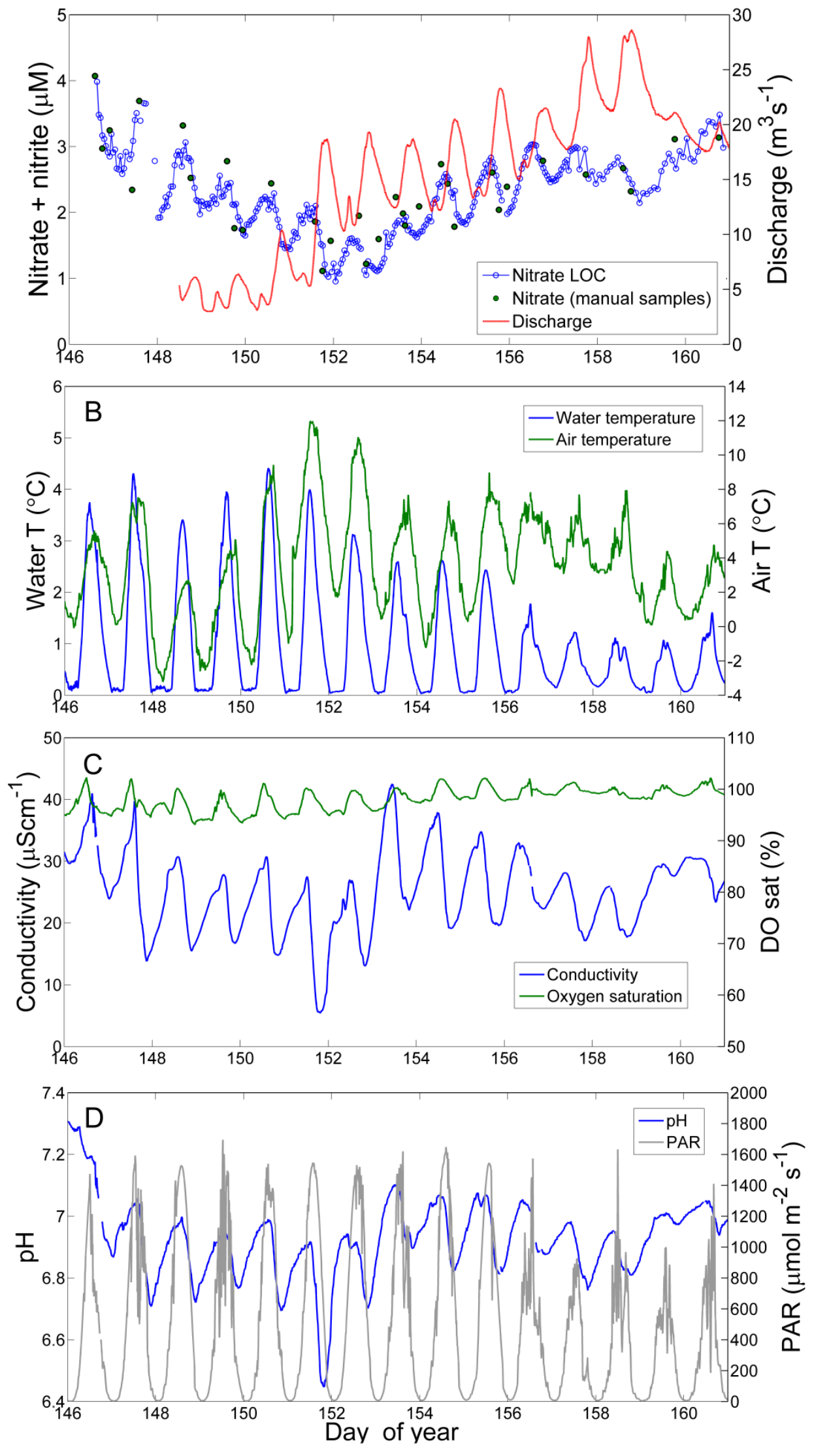
393 Figure 5: Plots showing average daily cycles of each of the parameters at KS (red) and LG (blue), created 394 by normalising to daily average, binning into timeslots and plotting the mean normalised value for each 395 timeslot (dots), the median (line) and +/- 1 standard deviation (error bars). Plots shown are A) Nitrate 396 plus nitrite, B) Dissolved oxygen saturation, C) PAR, D) Water temperature, E) Discharge, F) pH, G) 
Electrical conductivity, H) Air temperature.
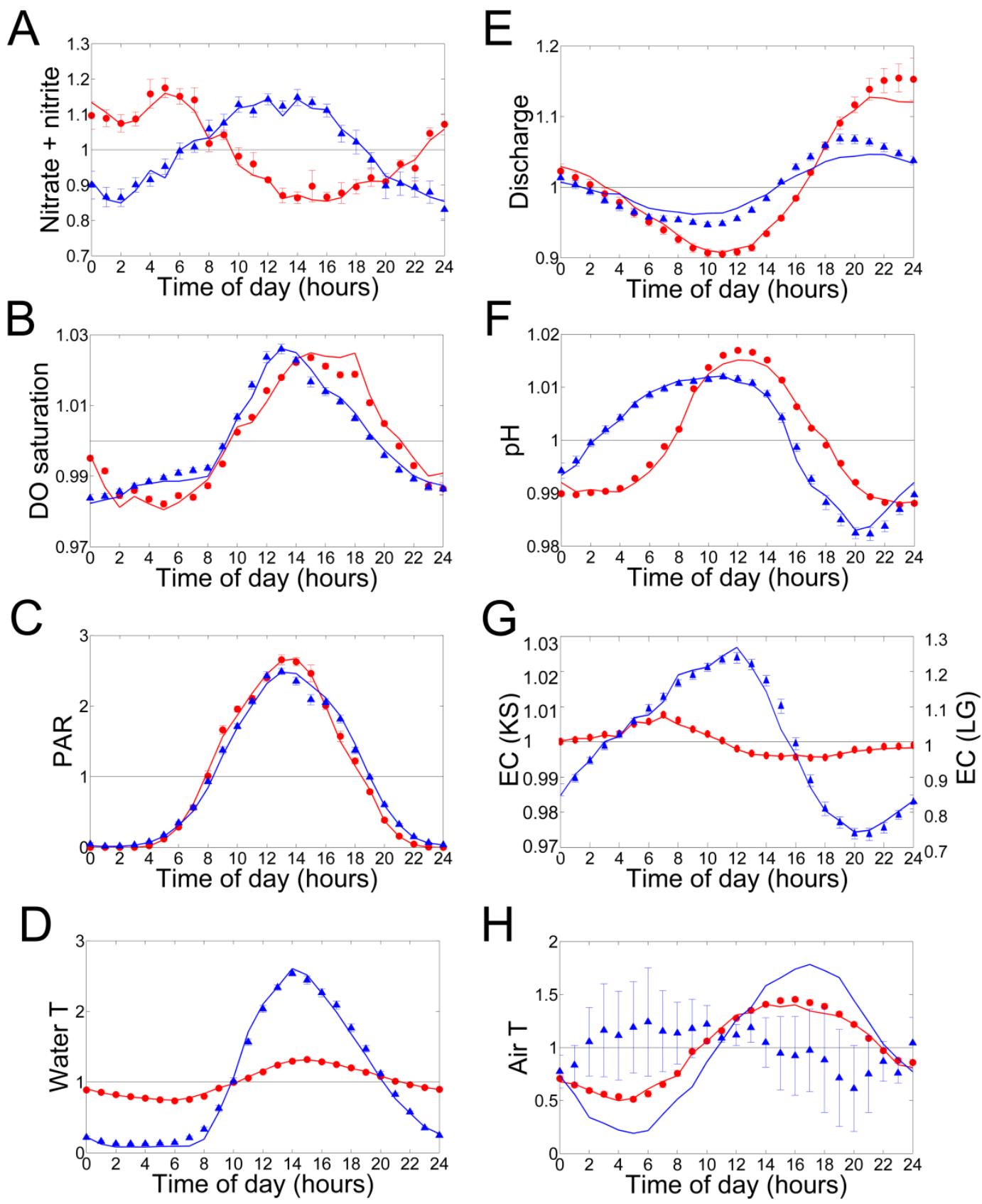

$\mathrm{H}$

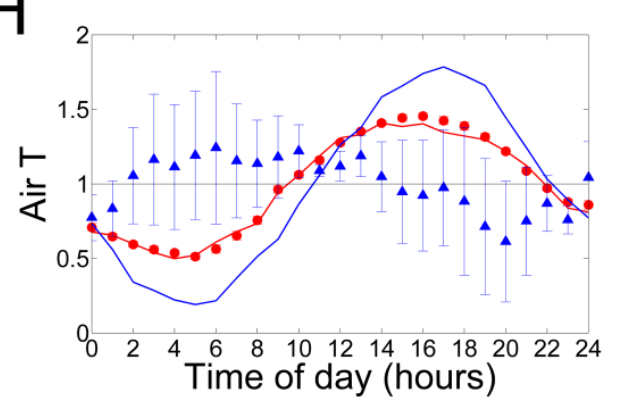

KS mean

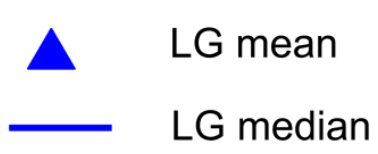

KS median 
401

402

403

404

405

406

407

408

409

410

411

412

413

414

415

416

417

418

419

420

421

422

423

424

425

426

427

428

429

430

431

432

433

434

\section{References}

(1) Telling, J.; Anesio, A. M.; Tranter, M.; Irvine-Fynn, T.; Hodson, A.; Butler, C.; Wadham, J. Nitrogen fixation on Arctic glaciers, Svalbard. J. Geophys. Res. 2011, 116, 2-9 DOI: 10.1029/2010JG001632.

(2) Telling, J.; Stibal, M.; Anesio, A. M.; Tranter, M.; Nias, I.; Cook, J.; Bellas, C.; Lis, G.; Wadham, J. L.; Sole, A.; et al. Microbial nitrogen cycling on the Greenland Ice Sheet. Biogeosciences 2012, 9, 2431-2442 DOI: 10.5194/bg-9-2431-2012.

(3) Wynn, P.; Hodson, A.; Heaton, T.; Chenery, S. Nitrate production beneath a High Arctic glacier, Svalbard. Chem. Geol. 2007, 244 (1-2), 88-102 DOI: 10.1016/j.chemgeo.2007.06.008.

(4) Boyd, E. S.; Lange, R. K.; Mitchell, A. C.; Havig, J. R.; Hamilton, T. L.; Lafrenière, M. J.; Shock, E. L.; Peters, J. W.; Skidmore, M. Diversity, abundance, and potential activity of nitrifying and nitrate-reducing microbial assemblages in a subglacial ecosystem. Appl. Environ. Microbiol. 2011, 77 (14), 4778-4787 DOI: 10.1128/AEM.00376-11.

(5) Wadham, J. L.; Hawkings, J.; Telling, J.; Chandler, D.; Alcock, J.; Lawson, E.; Kaur, P.; Bagshaw, E. A.; Tranter, M.; Tedstone, A.; et al. Sources, cycling and export of nitrogen on the Greenland Ice Sheet. Biogeosciences 2016, 13 (22), 1-30 DOI: 10.5194/bg-2015484.

(6) Perrette, M.; Yool, A.; Quartly, G. D.; Popova, E. E. Near-ubiquity of ice-edge blooms in the Arctic. Biogeosciences 2011, 8 (2), 515-524 DOI: 10.5194/bg-8-515-2011.

(7) Jensen, H. M.; Pedersen, L.; Burmeister, A.; Hansen, B. W. Pelagic primary production during summer along 65 to $72 \mathrm{~N}$ off West Greenland. Polar Biol. 1999, 21, 269-278 DOI: $10.1007 / \mathrm{s} 003000050362$.

(8) Hawkings, J. R.; Wadham, J. L.; Tranter, M.; Lawson, E.; Sole, A.; Cowton, T.; Tedstone, A. J.; Bartholomew, I.; Nienow, P.; Chandler, D.; et al. The effect of warming climate on nutrient and solute export from the Greenland Ice Sheet. Geochemical Perspect. Lett. 2015, 1, 94-104 DOI: 10.7185/geochemlet.1510.

(9) Wadham, J. L.; De’ath, R.; Monteiro, F. M.; Tranter, M.; Ridgwell, a.; Raiswell, R.; Tulaczyk, S. The potential role of the Antarctic Ice Sheet in global biogeochemical cycles. Earth Environ. Sci. Trans. R. Soc. Edinburgh 2013, 104, 55-67 DOI: 10.1017/S1755691013000108.

(10) Bagshaw, E. A.; Wadham, J. L.; Mowlem, M.; Tranter, M.; Eveness, J.; Fountain, a G.; Telling, J. Determination of dissolved oxygen in the cryosphere: a comprehensive laboratory and field evaluation of fiber optic sensors. Environ. Sci. Technol. 2011, 45 (2), 
700-705 DOI: 10.1021/es102571j.

(11) Bagshaw, E. A.; Beaton, A.; Wadham, J. L.; Mowlem, M.; Hawkings, J. R.; Tranter, M. Chemical sensors for in situ data collection in the cryosphere. TrAC - Trends Anal. Chem. 2016, 82, 348-357 DOI: 10.1016/j.trac.2016.06.016.

(12) Heffernan, J. B.; Cohen, M. J. Direct and indirect coupling of primary production and diel nitrate dynamics in a subtropical spring-fed river. Limnol. Ocean. 2010, 55 (2), 677-688.

(13) Pellerin, B. A.; Downing, B. D.; Kendall, C.; Dahlgren, R. a.; Kraus, T. E. C.; Saraceno, J.; Spencer, R. G. M.; Bergamaschi, B. a. Assessing the sources and magnitude of diurnal nitrate variability in the San Joaquin River (California) with an in situ optical nitrate sensor and dual nitrate isotopes. Freshw. Biol. 2009, 54 (2), 376-387 DOI: 10.1111/j.1365-2427.2008.02111.x.

(14) Pellerin, B. A.; Saraceno, J. F.; Shanley, J. B.; Sebestyen, S. D.; Aiken, G. R.; Wollheim, W. M.; Bergamaschi, B. a. Taking the pulse of snowmelt: in situ sensors reveal seasonal, event and diurnal patterns of nitrate and dissolved organic matter variability in an upland forest stream. Biogeochemistry 2011, 108 (3), 183-198 DOI: 10.1007/s10533-011-9589-8.

(15) Tranter, M.; Brown, G. H.; Hodson, A.; Gurnell, A. M.; Sharp, M. J. Variations in the nitrate concentration of glacial runoff in Alpine and sub-Polar environments. In Snow and Ice Covers: Interactions with the Atmosphere and Ecosystems (Proceedings of Yokohama Symposia J2 and J5); 1994; Vol. 1.

(16) Le Goff, T.; Braven, J.; Ebdon, L.; Scholefield, D. Automatic continuous river monitoring of nitrate using a novel ion-selective electrode. J. Environ. Monit. 2003, 5 (2), 353-358 DOI: 10.1039/b211140n.

(17) Scholefield, D.; Le Goff, T.; Braven, J.; Ebdon, L.; Long, T.; Butler, M. Concerted diurnal patterns in riverine nutrient concentrations and physical conditions. Sci. Total Environ. 2005, 344 (1-3), 201-210 DOI: 10.1016/j.scitotenv.2005.02.014.

(18) Daniel, A.; Birot, D.; Blain, S.; Treguer, P.; Leilde, B.; Menut, E. A submersible flowinjection analyser for the in-situ determination of nitrite and nitrate in coastal waters. Mar. Chem. 1995, 51 (1), 67-77 DOI: 10.1016/0304-4203(95)00052-S.

(19) Gardolinski, P. C. F. C.; David, A. R. J.; Worsfold, P. J. Miniature flow injection analyser for laboratory, shipboard and in situ monitoring of nitrate in estuarine and coastal waters. Talanta 2002, 58 (6), 1015-1027.

(20) Johnson, K.; Sakamoto-Arnold, C.; Beehler, C. Continuous determination of nitrate concentrations in situ. Deep. Res., Part A 1989, 36 (9), 1407-1413 DOI: 10.1016/01980149(89)90091-5. 
(21) Vuillemin, R.; Le Roux, D.; Dorval, P.; Bucas, K.; Sudreau, J. P.; Hamon, M.; Le Gall, C.; Sarradin, P. M. CHEMINI: A new in situ CHEmical MINIaturized analyzer. Deep. Res., Part I 2009, 56 (8), 1391-1399 DOI: 10.1016/j.dsr.2009.02.002.

(22) Glibert, P. M.; Kelly, V.; Alexander, J.; Codispoti, L. A.; Boicourt, W. C.; Trice, T. M.; Michael, B. In situ nutrient monitoring: A tool for capturing nutrient variability and the antecedent conditions that support algal blooms. Harmful Algae 2008, 8 (1), 175-181 DOI: 10.1016/j.hal.2008.08.013.

(23) Thouron, D.; Vuillemin, R.; Philippon, X.; Lourenço, A.; Provost, C.; Cruzado, A.; Garçon, V. An autonomous nutrient analyzer for oceanic long-term in situ biogeochemical monitoring. Anal. Chem. 2003, 75 (11), 2601-2609.

(24) Snyder, L.; Bowden, W. B. Nutrient dynamics in an oligotrophic arctic stream monitored in situ by wet chemistry methods. Water Resour. Res. 2014, 50 (3), 2039-2049 DOI: 10.1002/2013WR014317.

(25) Beaton, A. D.; Cardwell, C. L.; Thomas, R. S.; Sieben, V. J.; Legiret, F.; Waugh, E. M.; Statham, P. J.; Mowlem, M. C.; Morgan, H. Lab-on-Chip Measurement of Nitrate and Nitrite for In Situ Analysis of Natural Waters. Environ. Sci. Technol. 2012, 46 (17), 9548-9556 DOI: dx.doi.org/10.1021/es300419u.

(26) Nightingale, A. M.; Beaton, A. D.; Mowlem, M. C. Trends in microfluidic systems for in situ chemical analysis of natural waters. Sensors Actuators B Chem. 2015, 221, 13981405 DOI: 10.1016/j.snb.2015.07.091.

(27) Knudsen, N. T.; Yde, J. C.; Gasser, G. Suspended sediment transport in glacial meltwater during the initial quiescent phase after a major surge event at Kuannersuit Glacier, Greenland. Danish J. Geogr. 2003, 107 (1), 1-8.

(28) Hawkings, J.; Wadham, J.; Tranter, M.; Telling, J.; Bagshaw, E.; Beaton, A.; Simmons, S.-L.; Chandler, D.; Tedstone, A.; Nienow, P. The Greenland Ice Sheet as a hot spot of phosphorus weathering and export in the Arctic. Global Biogeochem. Cycles 2016, 30 (2), 191-210 DOI: 10.1002/2015GB005237.

(29) Bagshaw, E. A.; Lishman, B.; Wadham, J. L.; Bowden, J. a.; Burrow, S. G.; Clare, L. R.; Chandler, D. Novel wireless sensors for in situ measurement of sub-ice hydrologic systems. Ann. Glaciol. 2014, 55 (65), 41-50 DOI: 10.3189/2014AoG65A007.

(30) Bartholomew, I.; Nienow, P.; Sole, A.; Mair, D.; Cowton, T.; Palmer, S.; Wadham, J. Supraglacial forcing of subglacial drainage in the ablation zone of the Greenland ice sheet. Geophys. Res. Lett. 2011, 38 (8), 1-5 DOI: 10.1029/2011GL047063.

(31) Beaton, A. D.; Sieben, V. J.; Floquet, C. F. A.; Waugh, E. M.; Abi Kaed Bey, S.; Ogilvie, I. R. G.; Mowlem, M. C.; Morgan, H. An automated microfluidic colourimetric sensor 
applied in situ to determine nitrite concentration. Sens. Actuators, B 2011, 156 (2), 10091014 DOI: 10.1016/j.snb.2011.02.042.

(32) Yücel, M.; Beaton, A. D.; Dengler, M.; Mowlem, M. C.; Sohl, F.; Sommer, S. Nitrate and Nitrite Variability at the Seafloor of an Oxygen Minimum Zone Revealed by a Novel Microfluidic In-Situ Chemical Sensor. PLoS One 2015, 10, e0132785 DOI: 10.1371/journal.pone.0132785.

(33) Dubnick, A.; Kazemi, S.; Sharp, M.; Wadham, J.; Hawkings, J.; Beaton, A.; Lanoil, B. Hydrological controls on glacially exported microbial assemblages. J. Geophys. Res. Biogeosciences 2017, 122 (5), 1049-1061 DOI: 10.1002/2016JG003685.

(34) Kohler, T. J.; Žárský, J. D.; Yde, J. C.; Lamarche-Gagnon, G.; Hawkings, J. R.; Tedstone, A. J.; Wadham, J. L.; Box, J. E.; Beaton, A. D.; Stibal, M. Carbon dating reveals a seasonal progression in the source of particulate organic carbon exported from the Greenland Ice Sheet. Geophys. Res. Lett. 2017, 44 (12), 6209-6217 DOI: 10.1002/2017GL073219.

(35) Nimick, D. A.; Gammons, C. H.; Parker, S. R. Diel biogeochemical processes and their effect on the aqueous chemistry of streams: A review. Chem. Geol. 2011, 283 (1-2), 3-17 DOI: 10.1016/j.chemgeo.2010.08.017.

(36) Roberts, B. J.; Mulholland, P. J. In-stream biotic control on nutrient biogeochemistry in a forested stream, West Fork of Walker Branch. J. Geophys. Res. 2007, 112 (G4), G04002 DOI: $10.1029 / 2007 J G 000422$.

(37) Dokulil, M. T. Potamoplankton and primary productivity in the River Danube. Hydrobiologia 2014, 729, 209-227 DOI: 10.1007/s10750-013-1589-3.

(38) Johannessen, M.; Henriksen, A. Chemistry of snow melt water: changes in concentration during melting. Water Resour. Res. 1978, 14 (4), 615-619.

(39) Tranter, M.; Brimblecombe, P.; Davies, T. D.; Vincent, C. E.; Abrahams, P. W.; Blackwood, I. The composition of snowfall, snowpack and meltwater in the Scottish highlands-evidence for preferential elution. Atmos. Environ. 1986, 20 (3), 517-525 DOI: 10.1016/0004-6981(86)90092-2.

(40) Sickman, J. O.; Leydecker, A.; Chang, C. C. Y.; Kendall, C.; Melack, J. M.; Lucero, D. M.; Schimel, J. Mechanisms underlying export of $\mathrm{N}$ from high-elevation catchments during seasonal transitions. Biogeochemistry 2003, 64, 1-24 DOI: 10.1023/A:1024928317057.

(41) Tye, A. M.; Heaton, T. H. E. Chemical and isotopic characteristics of weathering and nitrogen release in non-glacial drainage waters on Arctic tundra. Geochim. Cosmochim. Acta 2007, 71 (February), 4188-4205 DOI: 10.1016/j.gca.2007.06.040. 
(42) Campbell, D. H.; Clow, D. W.; Ingersoll, G. P.; Mast, M. a.; Spahr, N. E.; Turk, J. T. Processes controlling the chemistry of two snowmelt-dominated streams in the Rocky Mountains. Water Resour. Res. 1995, 31 (11), 2811-2821 DOI: 10.1029/95WR02037.

(43) Hodson, A.; Anesio, A. M.; Tranter, M.; Fountain, A.; Osborn, M.; Priscu, J.; LaybournParry, J.; Sattler, B. Glacial Ecosystems. Ecol. Monogr. 2008, 78 (1), 41-67.

(44) Skidmore, M. L.; Foght, J. M.; Sharp, M. J. Microbial life beneath a high arctic glacier. Appl. Environ. Microbiol. 2000, 66 (8), 3214-3220.

(45) Holloway, J. M.; Dahlgren, R. A.; Hansen, B.; Casey, W. H. Contribution of bedrock nitrogen to high nitrate concentrations in stream water. Nature 1998, 395 (October), 785788.

(46) Holloway, J. M.; Dahlgren, R. A. Nitrogen in rock: Occurrences and biogeochemical implications. Global Biogeochem. Cycles 2002, 16 (4), 65 1-17 DOI: 10.1029/2002GB001862.

(47) Stevenson, F. J. Chemical state of the nitrogen in rocks. Geochim. Cosmochim. Acta 1962, 26, 797-809 DOI: https://doi.org/10.1016/0016-7037(62)90040-6.

(48) Mowlem, M.; Saw, K.; Brown, R.; Waugh, E.; Cardwell, C. L.; Wyatt, J.; Magiopoulos, I.; Keen, P.; Campbell, J.; Rundle, N.; et al. Probe technologies for clean sampling and measurement of subglacial lakes. Philos. Trans. R. Soc. London A Math. Phys. Eng. Sci. 2015, 374 (2059) DOI: 10.1098/rsta.2015.0267.

(49) Clinton-Bailey, G. S.; Grand, M. M.; Beaton, A. D.; Nightingale, A. M.; Owsianka, D. R.; Slavik, G. J.; Connelly, D. P.; Cardwell, C. L.; Mowlem, M. C. A Lab-on-Chip Analyzer for in Situ Measurement of Soluble Reactive Phosphate: Improved Phosphate Blue Assay and Application to Fluvial Monitoring. Environ. Sci. Technol. 2017, 51, 9989-9995 DOI: 10.1021/acs.est.7b01581.

(50) Grand, M. M.; Clinton-Bailey, G. S.; Beaton, A. D.; Schaap, A. M.; Johengen, T. H.; Tamburri, M. N.; Connelly, D. P.; Mowlem, M. C.; Achterberg, E. P. A Lab-On-Chip Phosphate Analyzer for Long-term In Situ Monitoring at Fixed Observatories : Optimization and Performance Evaluation in Estuarine and Oligotrophic Coastal. Front. Mar. Sci. 2017, 4 DOI: 10.3389/fmars.2017.00255. 